\title{
A Three-Dimensional Numerical and Multi-Objective Optimal Design of Wavy Plate-Fins Heat Exchangers
}

\author{
Chao Yu*D, Xiangyao Xue, Kui Shi and Mingzhen Shao
}

Changchun Institute of Optics, Fine Mechanics and Physics, Chinese Academy of Sciences, Changchun 130033, China; my691930402@163.com (X.X.); qw417345721@163.com (K.S.); ou910160194@163.com (M.S.)

* Correspondence: yuchao@ciomp.ac.cn

check for

updates

Citation: Yu, C.; Xue, X.; Shi, K.; Shao, M. A Three-Dimensional Numerical and Multi-Objective Optimal Design of Wavy Plate-Fins Heat Exchangers. Processes 2021, 9, 9. https:/ / dx.doi.org/ $10.3390 /$ pr9010009

Received: 3 December 2020

Accepted: 17 December 2020

Published: 23 December 2020

Publisher's Note: MDPI stays neutral with regard to jurisdictional claims in published maps and institutional affiliations.

Copyright: () 2020 by the authors. Licensee MDPI, Basel, Switzerland. This article is an open access article distributed under the terms and conditions of the Creative Commons Attribution (CC BY) license (https: / creativecommons.org/ licenses/by/4.0/).

\begin{abstract}
This paper presents a method for optimizing wavy plate-fin heat exchangers accurately and efficiently. It combines CFD simulation, Radical Basis Functions (RBF) with multi-objective optimization to improve the performance. The optimization of the Colburn factor $j$ and the friction coefficient $f$ is regarded as a multi-objective optimization problem, due to the existence of two contradictory goals. The approximation model was obtained by Radical Basis Functions, and the shape of the heat exchanger was optimized by multi-objective genetic algorithm (MOGA). The optimization results showed that $j$ increased by $17.62 \%$ and $f$ decreased by $20.76 \%$, indicating that the heat exchange efficiency was significantly enhanced and the fluid structure resistance reduced. Then, from the aspects of field synergy and tubulence energy, the performance advantage of the optimized structure was further confirmed.
\end{abstract}

Keywords: wavy plate-fins; multi-objective optimization; radical basis functions; computational fluid dynamics; field synergy

\section{Introduction}

As a kind of compact heat exchangers, wavy plate-fins (WPFs) heat exchangers have high efficiency and low weight, widespread applications in aerospace, automobile and power machinery. In WPFs heat exchangers, the hot and cold fluid flow through plate and fin respectively, as shown in Figure 1. Hence the excellent fin structure can effectively improve the efficiency of the heat exchangers.

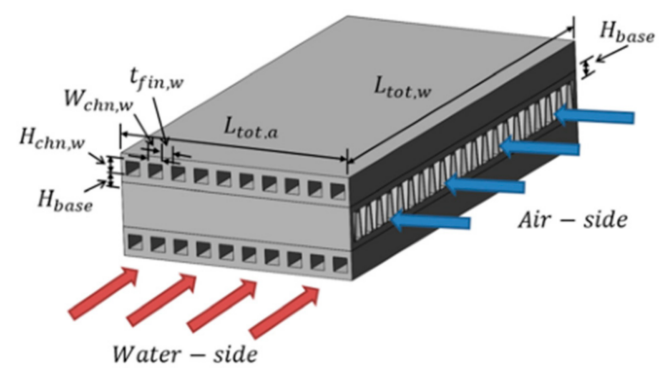

Figure 1. Typical wavy fin heat exchanger [1].

Martinus A. Arie [1] studied a new type of heat transfer enhanced microchannel by using a mathematical multi-objective optimization method, which maximized the performance coefficient. In order to obtain better fluid mixing and heat transfer efficiency at a low Reynold's number, Gongnan Xie [2] optimized the geometric shape of electronic radiator corrugated channels with the application of construction theory to minimize the overall thermal resistance and improve the thermal performance of structural corrugated channels. Based on the constructal theory, Yidan Song [3] studied dimensionless variables such as channel space, wavelength ratio and amplitude ratio, and obtained the optimal 
configuration of the wave fin-channels for the compact heat exchanger applied in the heat recovery system of micro turbine. Ankur Kumar [4] studied the thermal characteristics of the condenser and optimized the design from the aspects of heat transfer, area improvement coefficient, volume improvement coefficient and material requirements by using the threedimensional numerical simulation method. Jun Yanagimoto [5] studied the stamping of ultra-thin stainless steel sheet on finless heat exchangers by bidirectional corrugation with higher heat exchange efficiency and less surrounding air flow resistance. By using Pareto optimal strategy and a multi-objectives genetic algorithm, Limin Wang [6] obtained the optimal value of the pitch and height of the waveform board, so as to realize the maximum heat transfer capacity and minimum pumping power of the heat transfer surface of the waveform board.

During Taguchi grey relational analysis, Sunil Chamoli [7] studied the geometric parameters and flow parameters of the tube heat exchanger with perforated disk inserts. They optimized its Reynolds number, pitch ratio, diameter ratio and perforation index, then quantified the influence percentage of various factors on the performance of the heat exchanger tube. Sina Yarmohammadi [8] conducted an experimental study on condensation pressure drop and the heat transfer coefficient of the corrugated pipe. During the experiment, they discovered that the heat transfer coefficient and pressure drop of the corrugated pipe were $59 \%$ and $115 \%$ higher than that of the common pipe, respectively. $\mathrm{M}$. Khoshvaght Aliabadi [9] discussed the influence of three passive thermal transfer enhancement technologies on heat transfer and flow specification of corrugated plate fins. Masoud Asadi [10] studies the influence of the wavy-fin surface area on the thermal-hydraulic performance of the heat exchanger, and the influence of dimensionless parameters such as amplitude and length ratio, fin spacing ratio and channel cross section ratio on heat transfer characteristics and pressure drop. Giulio Lorenzini [11] applied the constructal design to minimize the overall thermal resistance of the assembly by optimizing the total volume, the volume of fin-material and the volume of the cavity. Mohammad Darvish Damavandi [12] used computational fluid dynamics, artificial neural networks and nondominated sorting Genetic Algorithm II to carry out optimization for the corrugated elliptic tube heat exchanger.

Gun Woo Kim [13] carried out a numerical simulation study on the crosscut-induced flow of the corrugated fin heat exchanger. The results showed that the heat transfer performance of the optimized crosscut fin was $23.81 \%$ higher than that of the general corrugated fin, and the pressure drop was also increased by 7.04\%. A. Ghorbanian [14] discussed the influence of wave amplitude, heat flux, darcy number and Rayleigh number on the Nusselt number, so as to solve the problem of physical optimization about the porous cavity under the action of nanofluids filling and thermal flow radiation. Gui Lu [15] proposed a new design method for corrugated microchannel radiator with porous fins, which verified that the new design reduced the pressure drop and thermal resistance compared with the traditional corrugated microchannel radiator. Nattadon Pannucharoenwong [16] conducted experiments to improve the tubular ice production facility by installing corrugated fins. They proved that the corrugated fins can significantly improve the performance of the ice making machine. Liehui Xiao [17] used a wind tunnel experiment to conduct a cooling enhancement heat transfer experiment on corrugated fin tube bundles, and measured the temperature distribution on the fin surface through a visual window. Jakub Krzysztof Grabski [18] analyzed the fluid in the corrugated pipe by the basic solution method and the Radial Basis Functions. They verified that the Nusselt number increased with the increase of amplitude and ripple number. By comparing the heat transfer rate, surface emissivity and convection coefficient under different fin geometry parameters, Arash Mahdavi [19] analyzed the heat transfer in the compact heat exchanger pipe, and verified that the heat transfer rate can significantly increase the heat transfer coefficient. Gun Woo Kim [20] conducted a numerical study on the optimal cross section length of the fin heat exchanger with different corrugated angles. They obtained the optimal heat transfer performance of 0.4 cross-cut reference length in all corrugated angles. Evangelos Bellos [21] studied 
the optimal number and location of the fin in the parabolic trough collector, and proved that the absorber with the fin in the lower part of the absorber and three fins in the lower part was optimal. M.J. Li [22] conducted an experimental study on a new type of plate fin heat exchanger, and verified that the heat transfer rate and pressure loss of the designed five-row fin heat exchanger surface were basically the same as that of the six-row corrugated heat exchanger surface. O.O. Adewumi [23] conducted numerical study on a microchannel heat sink with micro pin fin inserts for both fixed and variable axial lengths. Gongnan Xie [24-26] made numerical calculation on the laminar flow and heat dissipation performance, and the numerical results showed that the heat dissipation performance of the microchannel radiator of multilevel bifurcation flow is better than that of the corresponding straight channel radiator. Chichuan Wang [27] studied the gas-side performance of the herringbone corrugated finned tube heat exchanger under dehumidification.

The multi-objective optimization of micro pin-fin arrays was studied by Reddy $\mathrm{S}$ $R$ [28]. The numerical results show that, for a specified maximum temperature, optimized arrays with pin-fins having symmetric convex lens shapes create the lowest pressure drop, followed by the symmetric airfoil and circular cross-section pin-fins. In the work of Shi H P [29], the nonuniformity of fluid flow is focused on to improve the performance of a microchannel ceramic heat exchanger. The nonuniformity of fluid flow is reduced by $68.2 \%$ and pressure drop is increased by $6.6 \%$ by the optimization, which means the uniformity of fluid flow in the heat exchanger is improved significantly with just a little cost of pressure drop. An analysis of a radial, finned, shell and tube heat exchanger is carried out by Sadeghzadeh $\mathrm{H}$ [30], considering nine design parameters: tube arrangement, tube diameter, tube pitch, tube length, number of tubes, fin height, fin thickness, baffle spacing ratio and number of fins per unit length of tube. The optimization of the objective functions is performed using a non-dominated sorting genetic algorithm (NSGA-II), and compared against a one-objective algorithm, to find the best solutions.

In this research, we selected four main parameters of wavy fin and carried out multiobjective optimization to improve the performance of wavy plate-fin heat exchangers. The wavy fin height $h$, thickness $t$, spacing $s$ and amplitude $A$ were defined as the parameters variable to obtain the Colburn factor $j$ and friction factor $f$. Then, the maximum $j$ and minimum $f$ were chosen as the standards of wavy plate-fin heat exchangers. The optimal structural parameters of heat exchangers are obtained by Radical Basis Functions (RBF) and genetic algorithm (MOGA). Finally, the rationality of optimization is verified by comparing it with the original model.

\section{Structure Parameters of WPF Heat Exchangers}

In the engineering field, the requirement of higher heat dissipation efficiency is put forward for heat exchangers in a reasonable size range. Hence, a kind of WPF heat exchanger has been investigated, named SZ001. Its 3D model is shown in Figure 2 and its structural parameter was shown in Table 1. In the experiment of this heat exchanger, the gas and water flows through the wavy fin and plate, which are made of aluminum respectively. 


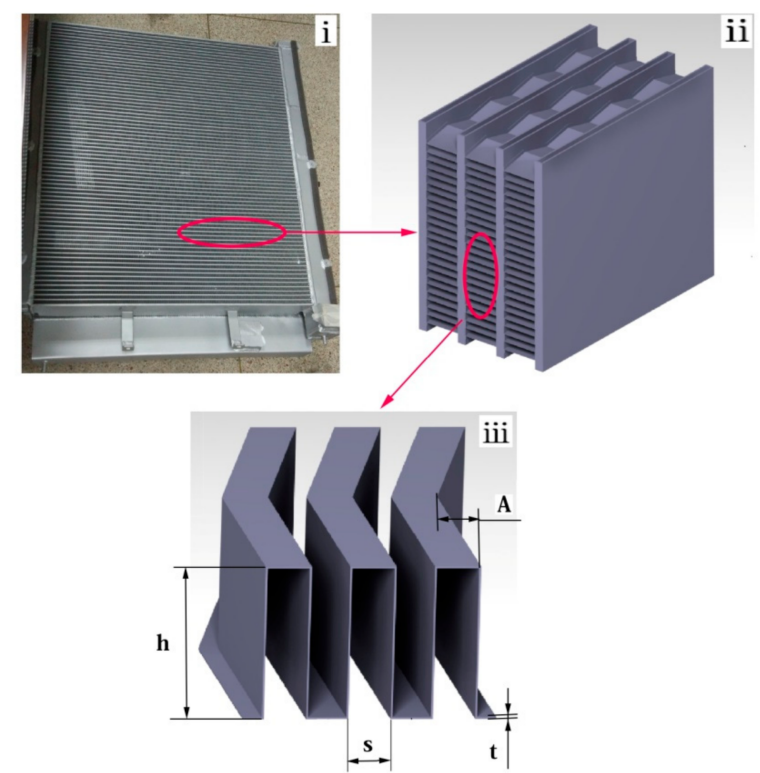

Figure 2. WPF heat exchanger model of experiment; (i) WPF heat exchanger; (ii) Heat exchanger core; (iii) Single channel.

Table 1. Values of structural parameters ( $\mathrm{mm})$.

\begin{tabular}{|c|c|c|c|c|c|}
\hline Fin Dimensions & Values & $\begin{array}{c}\text { Plate } \\
\text { Dimensions }\end{array}$ & Values & $\begin{array}{c}\text { Core } \\
\text { Dimensions }\end{array}$ & Values \\
\hline Fin height (h) & 8.00 & Plate length & 825 & Core width & 380 \\
\hline Fin spacing (2s) & 3.50 & Plate width & 56 & Core length & 825 \\
\hline Fin thickness (t) & 0.13 & $\begin{array}{c}\text { Plate } \\
\text { thickness }\end{array}$ & 2 & Core depth & 56 \\
\hline Fin amplitude (A) & 1.44 & Plate number & 37 & & \\
\hline Inner arc radius & 0.35 & & & & \\
\hline
\end{tabular}

\section{Numerical Simulation of Wavy Fin Heat Exchangers}

\subsection{Boundary Conditions}

The flow of air is a complex thermal flow in a corrugated duct. The CFD obtains the distribution characteristics of the flow field and the temperature field in the flow channel. The inlet air velocity of the heat exchanger is about $8 \mathrm{~m} / \mathrm{s}$, which means the Reynold's number $>2100$. So the RNG $k-\varepsilon$ model was employed to solve coupling of velocity and pressure in the governing equations.

The single channel geometry for numerical simulation is shown in detail in Figure 3. Considering the symmetry of the corrugated fin structure, a single flow channel with periodic boundary conditions is used for numerical simulation in order to reduce the time cost. The inlet wall is arranged as a velocity inlet wall. The inlet fluid velocity is $8 \mathrm{~m} / \mathrm{s}$ and the temperature is $50^{\circ} \mathrm{C}$. The fin contact wall surface is set as a thermostatic wall at a temperature of $90^{\circ} \mathrm{C}$. The outlet is set to a pressure outlet with a standard atmospheric pressure.

\subsection{Numerical Setting}

Ansys Fluent solves the governing equations using the finite volume method. SIMPLE algorithm and second-order upwind schemes are used to solve the convection term. The physical properties of fluid and solid can be found in Table 2. 


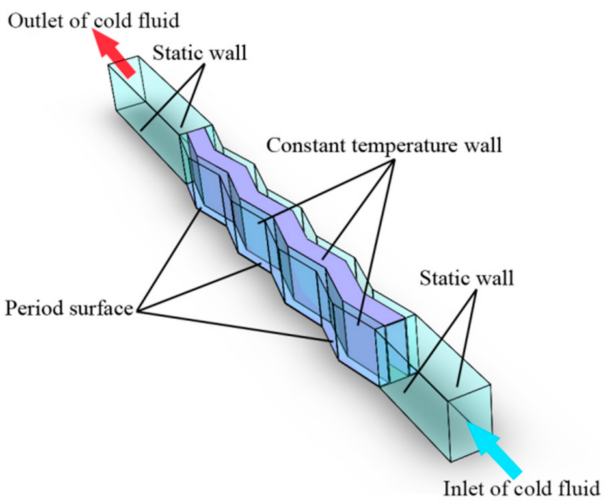

Figure 3. Single channel geometry for numerical simulation.

Table 2. Physical properties of fluid and solid.

\begin{tabular}{cccc}
\hline & Water & Air & Aluminum \\
\hline Density $\left(\mathrm{kg} / \mathrm{m}^{3}\right)$ & 998.2 & 1.23 & 2719 \\
Specific heat $(\mathrm{J} /(\mathrm{kg} \cdot \mathrm{K}))$ & 4182 & 1006.43 & 871 \\
Thermal conductivity & 0.6 & 0.0242 & 237 \\
$(\mathrm{~W} /(\mathrm{m} \cdot \mathrm{K}))$ & $8.81 \times 10^{-4}$ & $2.493 \times 10^{-5}$ & - \\
\hline Viscosity $(\mathrm{Pa} \cdot \mathrm{s})$ &
\end{tabular}

The Ansys mesh is used to discretize the computational domain. A hexahedral mesh is selected to obtain a more accurate simulation result and the mesh size of the layer near the wall is $0.1 \mathrm{~mm}(\mathrm{y}+<5)$, as shown in Figure 4. In the CFD verification process, the independence was studied under seven different grid solutions, in which the number of meshes are $139,873,163,016,182,023,201,754,220,944,242,153$ and 263,481. Nusselt number is an important parameter for evaluating the heat exchangers, so the optimal grid number is comprehensively evaluated according to the Nusselt number and the time required for calculation. As shown in Figure 5, with the increase in the number of grids, the calculation time is obviously extended, and the Nusselt number also tends to be stable. Considering the accuracy of the simulation and the computational cost, the number of grid cells is set at 210,754 to meet the requirements of this study.

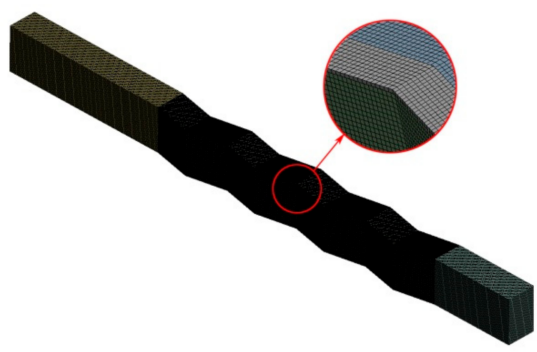

Figure 4. The gird for the entire computational domain. 


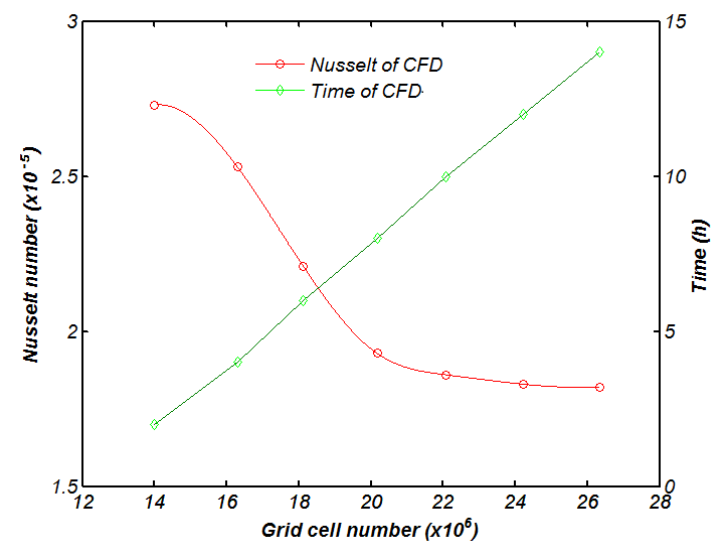

Figure 5. Grid independence verification.

\subsection{Comparison with the Experiment}

The target heat exchangers are tested experimentally. The high temperature coolant flows through the hot side of the heat exchangers, the air flows through the cold side of the heat exchangers, and the air flow sensor measures the temperature at the outlet. The actual test image is shown in Figure 6.

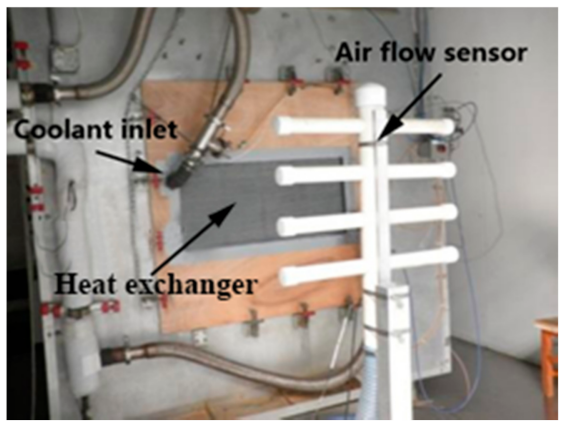

Figure 6. Experimental data collection.

Figure 7 shows that the CFD results are in good agreement with the experimental results. A series of data was calculated at a flow rate of 4-12 m/s to plot the characteristic curves of the differential pressure and heat transfer coefficient with air velocity, and the root mean square error (RMSE) of the differential pressure and heat transfer coefficient were $5.73 \%$ and $7.38 \%$, respectively. Considering the systematic error in the test, it can be known that the method of simulation has a high reliability.

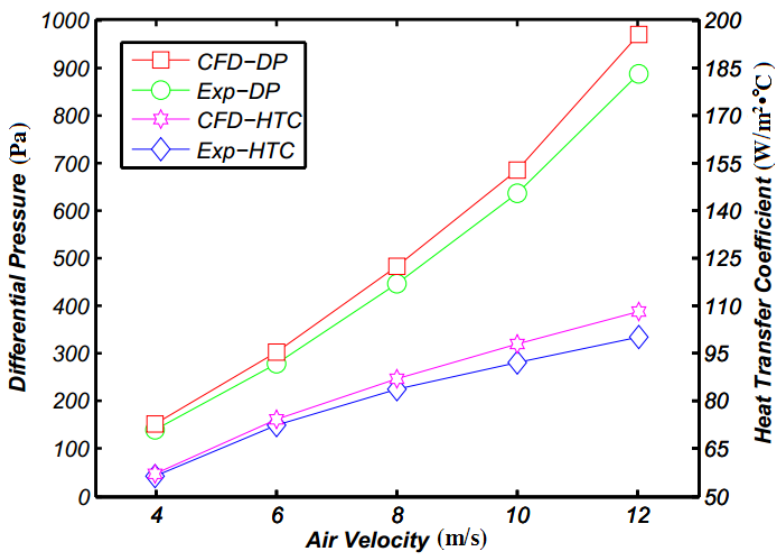

Figure 7. CFD result and experimental data. 


\section{Optimal Structure of Wavy Fin Heat Exchangers}

The classic optimization method aggregates multi-objective problems into a singleobjective problem by assigning weights to the target. But the Multi-Objective Genetic Algorithm (MOGA) is a typical method of searching the optimal frontier of Pareto based on Pareto sequencing and niche technology to improve population diversity and prevent premature convergence. In the calculation process of MOGA, an initial population is randomly generated, and the objective function of each point is calculated. Each individual in the population is sorted based on the Pareto optimal concept. The ranking method is to compare each member of the group with the number of all other individuals in the population that govern the associated individual. The optimal solution is determined according to the constraints. The sample points were created by using the experimental design method of Latin Hypercube Sampling (LHS). The entire flow chart is shown in Figure 8. In this research, we select four main parameters of wavy fin and carry out multi-objective optimization to improve the performance of wavy plate-fin heat exchangers. The optimal structural parameters of heat exchangers are obtained by Radical Basis Functions (RBF) and genetic algorithm (MOGA). Finally, the rationality of optimization is verified by comparing them with the original model.

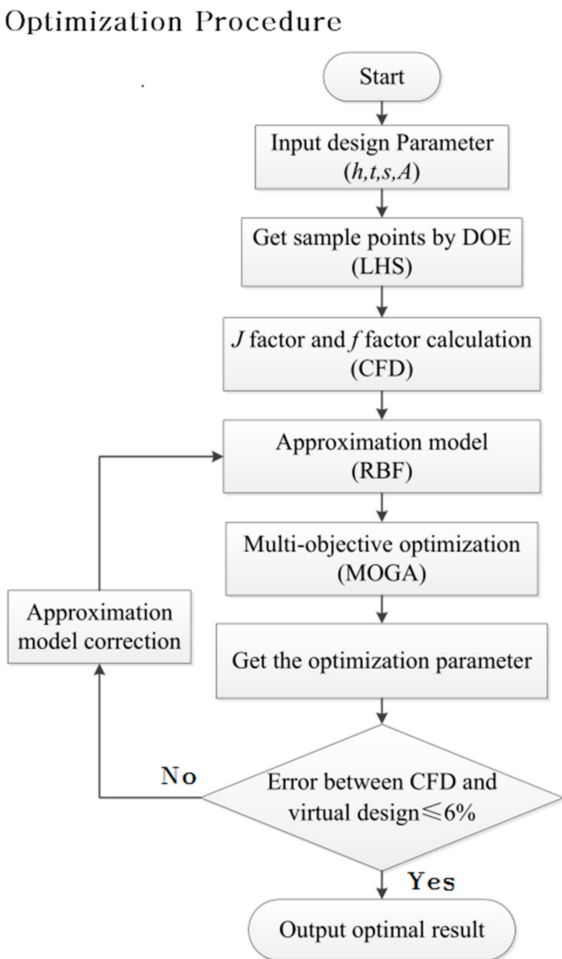

Figure 8. Optimization process.

Step1: Constraint condition

WPF heat exchanger shape optimization is designed to achieve high heat transfer capability and low fluid structure resistance. The larger $j$ represents a stronger heat transfer efficiency and a relatively complex structure. The smaller $f$ indicates that the fluid in the channel is smooth, the flow resistance is small, and the structure is relatively simple. Colburn factor $j$ and friction factor $f$ can be expressed as follows:

$$
\left\{\begin{array}{l}
j=\frac{N u}{R_{e} P_{r}^{1 / 3}} \\
f=\frac{2 \Delta P D}{\rho u^{2} L}
\end{array}\right.
$$


$\mathrm{Nu}, \mathrm{Re}$ and $\mathrm{Pr}$ are Nusselt number, Reynold's number and Prandtl number. They are defined as:

$$
\left\{\begin{array}{c}
D=\frac{4 S}{U}=\frac{4 s(h-t)}{2[s+(h-2 t)]}=\frac{2 s(h-t)}{s+h-2 t} \\
\operatorname{Re}=\frac{\rho D u}{\mu} \\
\operatorname{Pr}=\frac{\mu c_{p}}{\lambda} \\
N u=\frac{m c_{p} D\left(T_{\text {out }}-T_{\text {in }}\right)}{\lambda S \Delta t_{m}}
\end{array}\right.
$$

The design parameters are wavy fin height $h$, wavy fin spacing $s$, wavy fin amplitude $A$ and wavy fin thickness $t$. According to $j$ and $f$, the objective function can be defined as follows.

$$
F(X)=F\left(x_{1}, x_{2}, x_{3}, x_{4}\right)=F(h, s, A, t)
$$

According to the range of heat transfer performance parameters [31], the wavy fin structural parameters are:

$$
4<h<12,1<s<3.5,1<A<3,0.06<t<0.2 .
$$

The largest $j$ and the smallest $f$ are chosen as the objective function for optimization, which is defined as follows.

$$
\begin{aligned}
& \max j\left(x_{i}\right)=\max F(h, s, A, t) \\
& \min f\left(x_{i}\right)=\min F(h, s, A, t)
\end{aligned}
$$

Step2: Sample selection rule

Due to the non-linear relationship between structural parameters and performance, LHS was used to acquire 50 sets of sample point to construct three-dimensional models (parameters listed in Table A1).

Step3: Approximation model

Here, the RBF algorithm is applied to obtain the approximation model [32]:

$$
y=\sum_{i=1}^{n} w_{i j} \exp \left(-\frac{n}{2 \sigma^{2}}\left\|x_{p}-c_{i}\right\|^{2}\right)
$$

where $w_{i j}$ is the weight of the neurons between the hidden layer and the output layer, $\sigma$ is the variance of basis function, $n$ is the number of sample and $c_{i}$ is the center of clustering. An additional non-linear relationship between parameters and performances can be obtained from the calculation of each sample point data from CFD, shown in Figure A1.

The approximate relationship between the design variable and the objective function is determined by the above principle. The 20 sets of control sample points selected in Table A2 were used to compare the CFD calculations of these points with the approximate model budget values to determine the availability of the approximate model. The RMSE is chosen as the criterion for approximating the usability of the model, and its equation is shown in Equation (7).

$$
R M S E=\sqrt{\left[\sum_{i=1}^{n}\left(X_{C F D}-X_{\text {model }}\right)^{2}\right] / n}
$$

Step4: Multi-objective Optimization

MOGA is used to solve the optimal solution in the approximate model. Set the maximum value of $j / f$ as the objective function. 


\section{Optimal Result Analysis}

The Pareto front reflects the optimal tradeoff between different optimization objectives, as shown in Figure 9. Through the above procedure, as shown in Table 3, the corresponding optimized structural parameters $h, s, A, t$ values are obtained at the $j / f$ maximum value. Table 4 shows the results of Colburn factor $j$ and friction factor $f$, calculated by the approximate model and CFD optimization respectively under the corresponding optimization results. The comparison results show that the approximate model's Colburn factor $j$ and friction factor $f$ errors are below $5 \%$, verifying the reliability of the approximate model again. Figure 10 is a comparison of the original model and the optimized model.

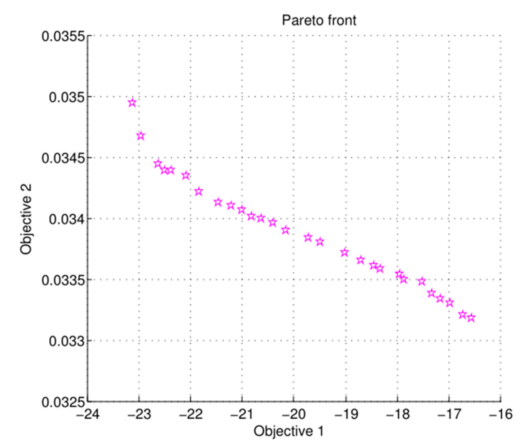

Figure 9. The Pareto front of optimization.

Table 3. Structural parameters before and after optimization.

\begin{tabular}{ccccccc}
\hline & $\boldsymbol{h}(\mathbf{m m})$ & $\boldsymbol{s}(\mathbf{m m})$ & $\boldsymbol{A}(\mathbf{m m})$ & $\boldsymbol{t}(\mathbf{m m})$ & $j$ & $f$ \\
\hline Before optimization & 8.00 & 1.75 & 1.44 & 0.13 & 19.65 & 0.044 \\
After optimization & 7.90 & 2.40 & 1.35 & 0.12 & 23.11 & 0.035 \\
Variation & $1.25 \%$ & $37.1 \%$ & $6.25 \%$ & $7.7 \%$ & $17.62 \%$ & $20.76 \%$ \\
\hline
\end{tabular}

Table 4. Compared between the CFD and approximation.

\begin{tabular}{ccc}
\hline & $j$ & $f$ \\
\hline CFD & 22.07 & 0.033 \\
Approximation & 23.11 & 0.035 \\
Error & $4.47 \%$ & $4.82 \%$ \\
\hline
\end{tabular}
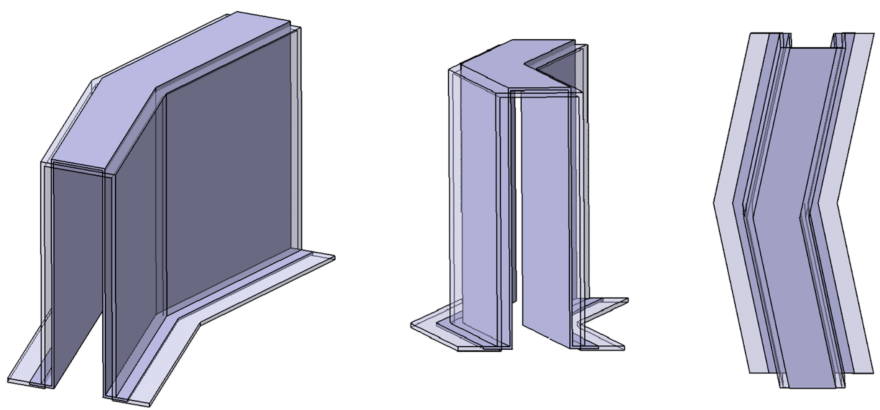

Figure 10. Comparison between the optimization model and the original models (the entity model is the original model; the virtual model is the optimization model).

The Figure 11 shows a longitudinal section CFD cloud map of the optimized structure and the original structure in terms of flow rate, pressure, and temperature. Overall, the distribution of cloud maps before and after optimization is basically the same. However, it can be seen from the near wall area that the optimized fluid velocity is gentle, the pressure 
is small, the temperature distribution is more uniform, and the heat dissipation effect is more obvious. Compared with the average values of the longitudinal sections, the velocity field increased by $0.01 \%$, the pressure field decreased by $36 \%$ and the temperature decreased by $6 \%$.

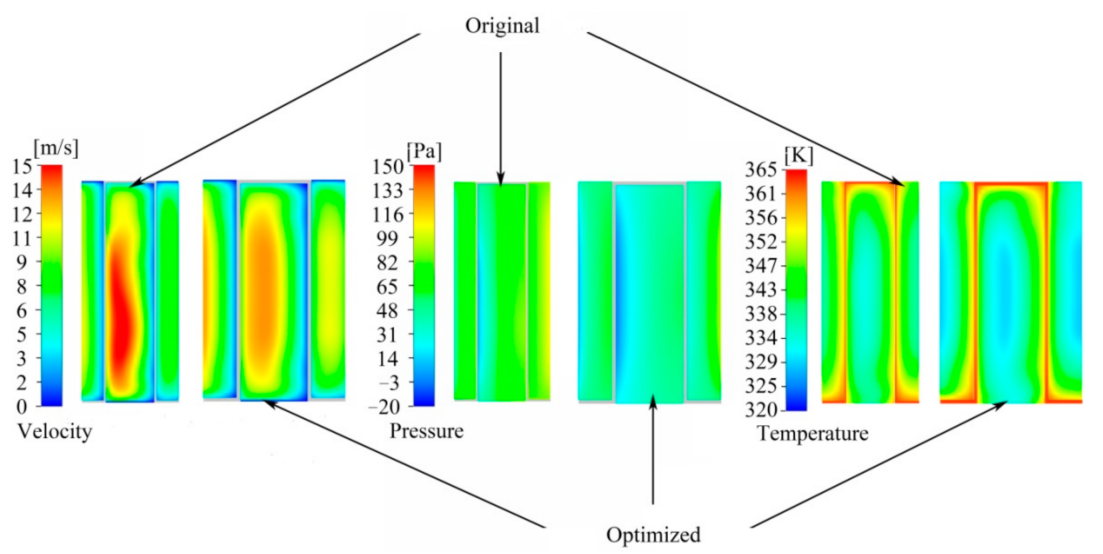

Figure 11. Comparison longitudinal section between the optimization and the original.

The Figure 12 shows a cross-sectional CFD cloud map of the optimized structure and the original structure in terms of flow rate, pressure, and temperature. When the fluid passes through the warming wall, the pressure gradually decreases and the temperature gradually rises. The differential pressure of the optimized structure is smaller, $33 \%$ less than the original structure, and the differential temperature increase is $5 \%$. The optimized structure has an equivalent diameter of 3.67 , while the original structure has an equivalent diameter of 1.77 , an increase of $52 \%$.

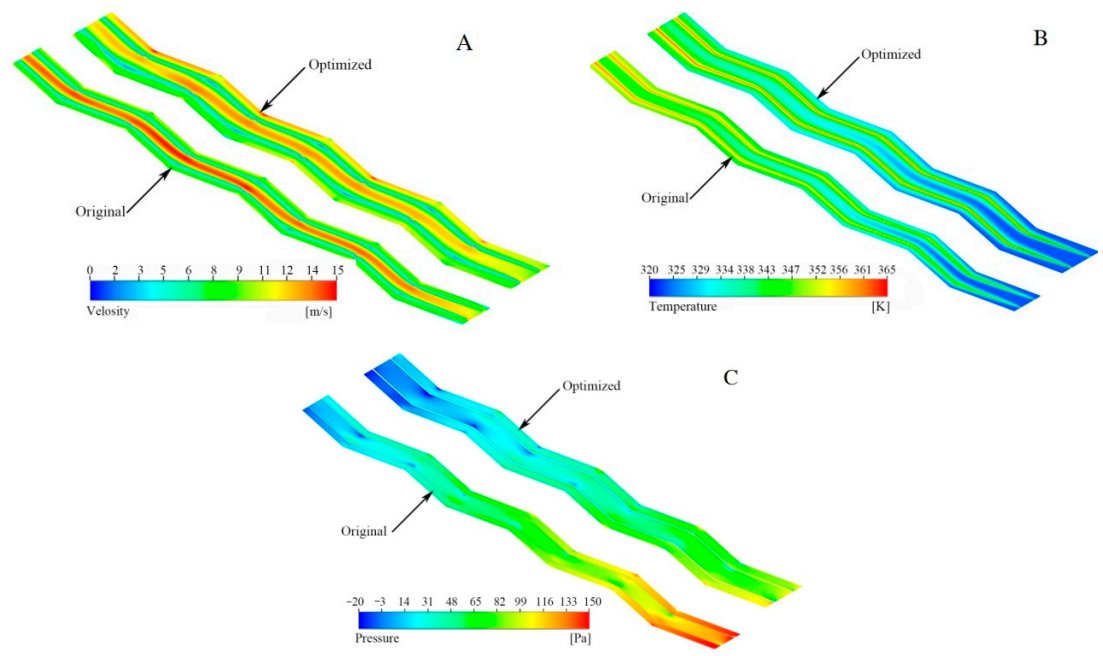

Figure 12. Comparison transverse section between the optimization and the original; (A) Velocity; (B) Temperature; (C) Pressure.

In summary, although the optimal diameter of the optimized structure is increased, the frictional resistance of the fluid is reduced, the heat transfer capacity is enhanced, and the performance of the optimized wavy fin heat exchanger is improved. 


\section{Discussion}

\subsection{The Field Synergy Analysis}

In conduction and convection problems, the presence of a heat source causes an increase in heat flux at the boundary. Among these problems, there are two basic vector fields: velocity and temperature gradient. The synergistic effect of the two vector fields also plays an important role [33]. In this study, the field synergy principle was introduced to evaluate WPFs. Figure 13 shows the relationship between physical fields. The amount of field synergy is defined as follows [34]:

$$
\left\{\begin{array}{c}
\beta=\arccos \frac{U \cdot \nabla T}{|U||\nabla T|} \\
\theta=\arccos \frac{U \cdot \nabla p}{|U||\nabla p|} \\
\gamma=\arccos \frac{\nabla T \cdot \nabla u}{|\nabla T||\nabla u|}
\end{array}\right.
$$

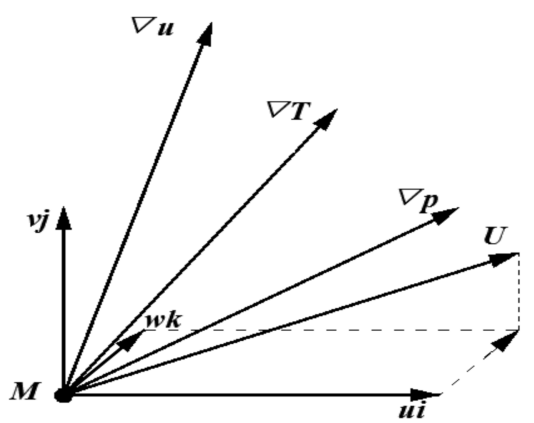

Figure 13. The physical properties of point $M$.

As shown in Equation (8), the $\beta$ is the included angle between the velocity vector and the temperature gradient, which represents the convective heat transfer intensity between the fluid and the tube wall. The $\theta$ represents the angle between the velocity vector and the pressure gradient, indicating the flow resistance. The $\gamma$ represents the angle between the temperature gradient and the velocity gradient, which characterizes convective intensity and drag reduction, and indicates the overall heat transfer capacity.

\subsubsection{Synergy Angle $\beta$ between Velocity and Temperature Gradient}

Figure 14 shows a comparison between the velocity field and the temperature gradient field in the same position of the flow channel before and after optimization. According to the heat transfer principle, cold air flows along the fins. At the same time, the fins continually transfer heat flux through convection, the direction of which is perpendicular to the fins, so the velocity direction tends to be perpendicular to the temperature gradient. In addition, at the tortuous portion of the fin, the heat transfer capability is remarkably enhanced, accompanied by a significant decrease in the synergy angle. Overall, the optimized model achieves a smaller $\beta$ and a better heat transfer performance.

\subsubsection{Synergy Angle $\theta$ between Velocity and Pressure Gradient}

The synergy angle $\theta$ between the velocity vector and the pressure gradient is shown in Figure 15. It can be found that the synergy angles of the two models are relatively similar. At the tortuous point, the fins prevent air from flowing, resulting in a deviation between the direction of flow and the direction of the driving force. The synergy angle is then increased here and the flow resistance is increased accordingly. In fact, in other places, it is obvious that the coordination angle of the optimization model is smaller than the coordination angle of the original model. Combined with the above pressure distribution, it can be 
known that although the pressure drop in the optimized model is large, a reasonable layout can reduce the synergy angle to reduce the friction coefficient $f$.

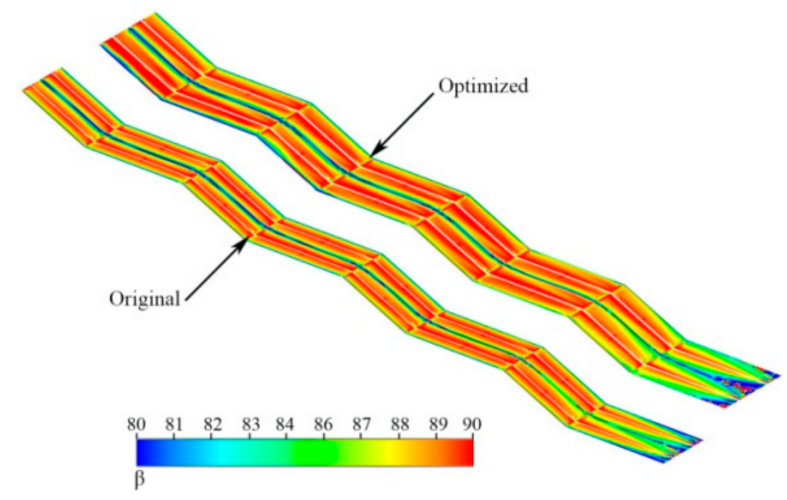

Figure 14. Comparison of synergy angle $\beta$.

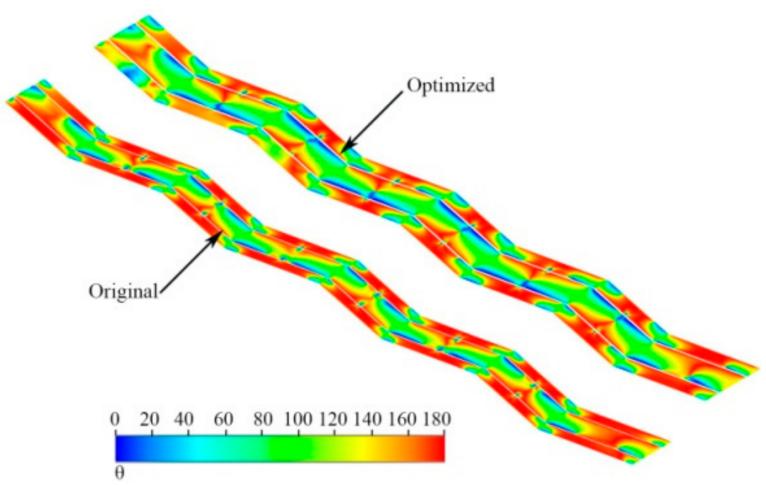

Figure 15. Comparison of synergy angle $\theta$.

\subsubsection{Synergy Angle $\gamma$ between Velocity Gradient and Temperature Gradient}

A comparison of the coordination angle $\gamma$ is shown in Figure 16. It is well known that a larger $\gamma$ indicates a better total heat transfer capacity. Therefore, the relatively large $\gamma$ obtained by the optimization model shows an improvement in performance. It has also been found that $\gamma$ near the fin turns is larger than other locations in the WPFs, indicating that major heat transfer has occurred here.

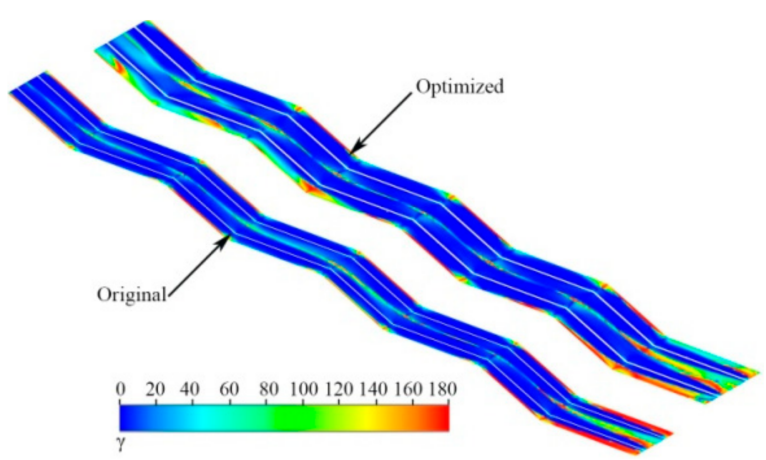

Figure 16. Comparison of synergy angle $\gamma$.

In summary, for the optimized model, the $\beta$ and $\theta$ were lower and $\gamma$ was higher, indicating better heat transfer. The analysis of the flow field characteristics of the optimization model above is also verified better through the field synergy analysis, which better explains the rationality of the optimization model. 


\subsection{Tubulence Energy}

In addition to the macroscopic representation of the flow field, the turbulent kinetic energy of the fluid also changes under the action of fins. The vortex phenomenon occurs in the flow field under the action of turbulent kinetic energy. The vortex can destroy the fluid boundary layer with large thermal resistance near the wall surface, thus improving the heat transfer efficiency of fins and improving the heat exchanger performance. Therefore, the turbulent kinetic energy is used to represent the turbulence pulsation intensity of the fluid in the turbulence model, which can be expressed as follows:

$$
E=\frac{1}{2}\left(\overline{u^{\prime 2}}+\overline{v^{\prime 2}}+\overline{w^{\prime 2}}\right)
$$

where, $u^{\prime}, v^{\prime}$, and $w^{\prime}$ are the pulsation velocity of the fluid in the direction of $\mathrm{X}, \mathrm{Y}$ and $\mathrm{Z}$ respectively. The value is the difference between the actual velocity and the average velocity of the particle in the velocity direction.

As shown in Figure 17, the turbulent kinetic energy of the fluid on the wavy fin should be gradually increased, and the highest turbulent kinetic energy appears at the peak of the fin wave. This is because the fluid impinges on the fin wall to form a similar efflux effect. Under the interaction between the fluid and the wall surface, the reverse flow occurs and collides with the incoming fluid points, which results in a large velocity pulsation and thus increases the turbulent kinetic energy. It also affects the region behind the fin crest. In the far region after the crest, the fluid flows smoothly under the influence of wall viscous force, and the velocity pulsation decreases. From the perspective of turbulent kinetic energy, the optimized fin turbulent kinetic energy is smaller, but the flow resistance is also smaller. At the same inlet velocity, the fin heat transfer performance is better.

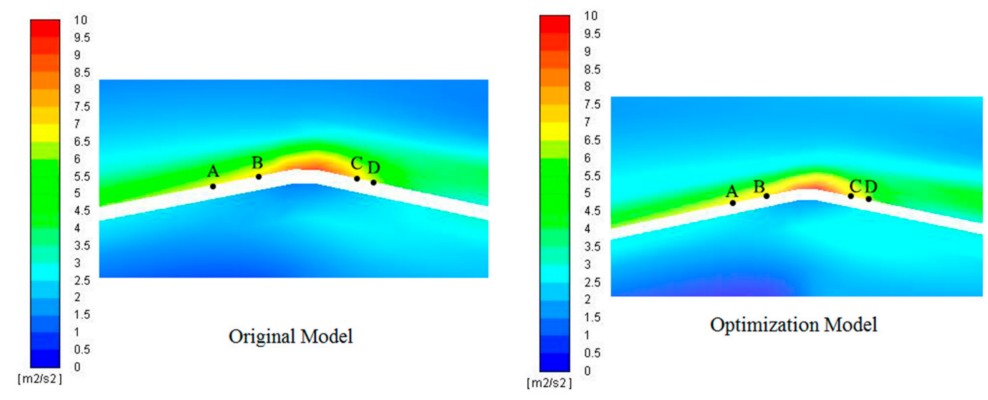

Figure 17. The turbulent kinetic energy distribution of the original model and optimization model; (A is the starting point of the reverse pressure; $\mathrm{B}$ is the separation point; $\mathrm{C}$ is the reattachment point; $\mathrm{D}$ is the end point of the reverse pressure).

Because the presence of corrugated fins destroys the original flow state of the fluid, there exists a region of adverse pressure gradient $(\partial P / \partial x>0)$ opposite to the normal pressure gradient $(\partial P / \partial x<0)$ in the bend region of the flow passage. The point $(\partial P / \partial x=0)$ with a pressure gradient of 0 along the direction of fluid flow is defined as the starting point of adverse pressure and the ending point of adverse pressure, respectively. In the region of the adverse pressure gradient, the boundary layer begins to separate, when the flow velocity of the fluid decreases gradually under the action of adverse pressure and reaches zero with the flow velocity of the wall. From the physical model, the separation point is a position where the radial velocity gradient perpendicular to the flow direction is zero $(\partial u / \partial y=0)$. After the separation point, the flow velocity in the direction opposite to the main flow $(\partial u / \partial x<0)$ appears under the action of reverse pressure, thus forming a vortex that wants to break away from the main flow. This vortex is called a secondary flow.

As the fluid moves in the region of adverse pressure gradient, the adverse pressure gradually decreases until the separation point occurs again, that is, the radial velocity gradient perpendicular to the flow direction of the fluid is zero $(\partial u / \partial y=0)$. At this point, the vortex detachment process ends, and this position is called the reattachment 
point. According to the above theory, the separation point and the reattachment point must appear between the starting point and the ending point of the adverse pressure gradient. At the same time, the fluid forms an impact effect similar to the efflux on the incoming flow surface of the corrugated fin, and the boundary layer at the position of efflux is the thinnest.

By comparing the fluid turbulent kinetic energy of the original and optimized model, it can be seen that the optimized inverse pressure gradient region is larger than that of the original one, the initial point $\mathrm{A}$ of the inverse pressure gradient is also earlier, and the termination point of the inverse pressure gradient is also more backward. In the reverse pressure region, the secondary reflux velocity of the optimized fin is greater than that of the original fin, which also indicates that the secondary flow intensity of the optimized fin flow field is higher. Due to the enhancement of secondary flows, the near-wall boundary layer of the fluid is effectively destroyed, which is beneficial to the improvement of fin heat transfer efficiency.

\section{Conclusions}

The wavy fin heat exchangers were selected as the research object, and the fin structure was optimized by RBF and MOGA. After optimization, the Colburn factor increased by $17.62 \%$, and the friction coefficient decreased by $20.76 \%$, showing a significant improvement. Then, the internal flow fields involving temperature, pressure and velocity were qualitatively compared to further emphasize the optimization effect. After optimization, the air temperature increased by $5 \%$ and the pressure drop was reduced by $33 \%$; the optimized speed was also significantly improved. In turbulent kinetic energy, the optimized model structure is more reasonable. It can be seen that the optimized inverse pressure gradient region is larger than that of the original one. The initial point A of the inverse pressure gradient is earlier, and the termination point of the inverse pressure gradient is also more backward. Overall, the optimized WPFs heat transfer rate can fully meet the performance requirements of the radiator, and the field synergy number is analyzed. They are very meaningful for understanding the optimization principle of the heat exchanger and can better guide the structural design optimization of the heat exchanger.

This paper combines multi-objective optimization methods and 3D CFD simulations for heat exchanger structure forecasting, rather than through expensive, time-consuming experiments. Multi-objective optimization of plate-fin heat exchangers focuses on improving heat transfer performance without considering economics. Therefore, it is necessary to combine the heat transfer performance and economic efficiency of the heat exchanger according to actual needs for optimal design.

Author Contributions: Conceptualization, C.Y.; methodology, C.Y.; software, X.X.; validation, K.S.; formal analysis, K.S.; investigation, X.X.; resources, M.S.; data curation, M.S.; writing—original draft preparation, C.Y.; writing-review and editing, C.Y.; visualization, M.S.; supervision, X.X.; project administration, X.X.; funding acquisition, X.X. All authors have read and agreed to the published version of the manuscript.

Funding: This research received no external funding.

Acknowledgments: The work reported in this paper is supported by State Key Laboratory of Laser Interaction with Matter, Changchun Institute of Optics, Fine Mechanics and Physics, Chinese Academy of Sciences.

Conflicts of Interest: The authors declare no conflict of interest. 


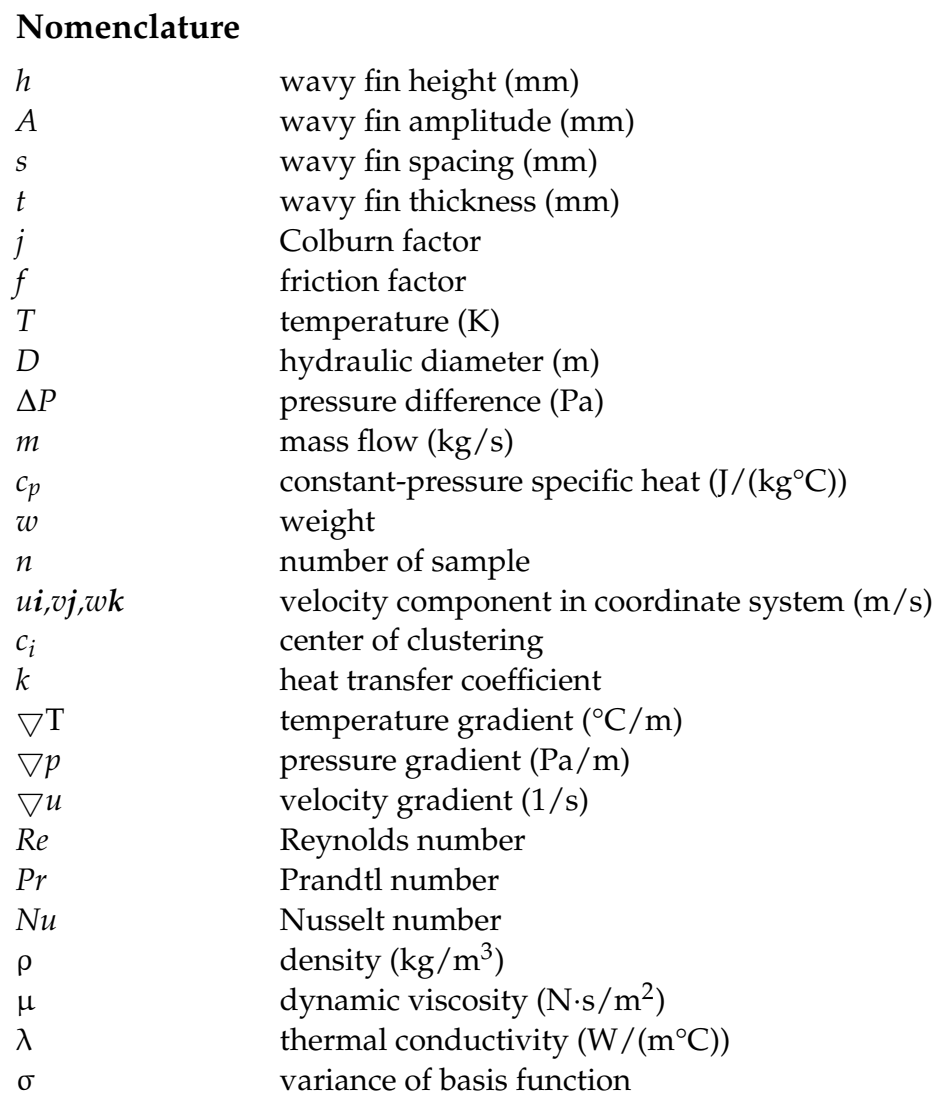

Appendix A

Table A1. 50 sets of structural parameters sample points.

\begin{tabular}{|c|c|c|c|c|c|c|c|c|c|}
\hline Code & $\begin{array}{c}h \\
(\mathrm{~mm})\end{array}$ & $\begin{array}{c}t \\
(\mathrm{~mm})\end{array}$ & $\begin{array}{c}s \\
(\mathrm{~mm})\end{array}$ & $\begin{array}{c}A \\
(\mathrm{~mm})\end{array}$ & Code & $\begin{array}{c}h \\
(\mathrm{~mm})\end{array}$ & $\begin{array}{c}t \\
(\mathrm{~mm})\end{array}$ & $\begin{array}{c}s \\
(\mathrm{~mm})\end{array}$ & $\begin{array}{c}A \\
(\mathrm{~mm})\end{array}$ \\
\hline 1 & 7.7 & 0.12 & 1 & 1.44 & 26 & 5.94 & 0.1 & 1.98 & 1.76 \\
\hline 2 & 6.32 & 0.1 & 1.32 & 2.3 & 27 & 8.74 & 0.16 & 2 & 2.4 \\
\hline 3 & 5.24 & 0.18 & 1.54 & 1.04 & 28 & 9.38 & 0.1 & 1.34 & 2.72 \\
\hline 4 & 4.44 & 0.14 & 1.3 & 2.72 & 29 & 5.36 & 0.08 & 2.24 & 2.44 \\
\hline 5 & 5.52 & 0.16 & 2.46 & 1.32 & 30 & 7.8 & 0.14 & 2.4 & 1.18 \\
\hline 6 & 5.8 & 0.1 & 2.44 & 1.54 & 31 & 10.1 & 0.1 & 1.4 & 2.58 \\
\hline 7 & 10.34 & 0.16 & 1.74 & 1.38 & 32 & 11.62 & 0.08 & 1.12 & 2.96 \\
\hline 8 & 6.44 & 0.14 & 2.48 & 2.42 & 33 & 7.14 & 0.12 & 2.06 & 1.62 \\
\hline 9 & 9.12 & 0.08 & 1.6 & 2.66 & 34 & 4.12 & 0.12 & 1.2 & 1.3 \\
\hline 10 & 4.66 & 0.14 & 1.14 & 2.22 & 35 & 8.36 & 0.06 & 2.34 & 1.08 \\
\hline 11 & 6.9 & 0.14 & 1.84 & 2.04 & 36 & 8.8 & 0.1 & 1.6 & 1.94 \\
\hline 12 & 8.16 & 0.12 & 2.38 & 1.82 & 37 & 7.98 & 0.16 & 1.66 & 1.16 \\
\hline 13 & 4.34 & 0.16 & 1.82 & 2.18 & 38 & 8.52 & 0.16 & 1.78 & 1.86 \\
\hline 14 & 10.78 & 0.16 & 2.2 & 2.94 & 39 & 10.56 & 0.18 & 1.38 & 1.7 \\
\hline 15 & 4.98 & 0.14 & 2.04 & 1.64 & 40 & 9.6 & 0.16 & 2.1 & 2.62 \\
\hline 16 & 9.68 & 0.14 & 1.7 & 2.34 & 41 & 5.56 & 0.08 & 1.04 & 2.48 \\
\hline 17 & 9.3 & 0.08 & 1.88 & 1.26 & 42 & 9.92 & 0.14 & 1.96 & 2.82 \\
\hline 18 & 8.94 & 0.08 & 1.42 & 1.96 & 43 & 4.24 & 0.08 & 1.92 & 1.08 \\
\hline 19 & 6.74 & 0.16 & 2.14 & 1.76 & 44 & 5.04 & 0.06 & 1.76 & 1.9 \\
\hline 20 & 11.38 & 0.18 & 1.24 & 1.58 & 45 & 8.34 & 0.1 & 2.26 & 2.84 \\
\hline 21 & 6.24 & 0.08 & 2.14 & 2.9 & 46 & 7.08 & 0.12 & 2.3 & 2.26 \\
\hline 22 & 6.54 & 0.12 & 2.2 & 2.56 & 47 & 7.6 & 0.18 & 1.66 & 2.02 \\
\hline 23 & 9.82 & 0.12 & 1.5 & 2.76 & 48 & 7.34 & 0.06 & 1.46 & 2.14 \\
\hline 24 & 7.44 & 0.12 & 1.08 & 1.24 & 49 & 11.22 & 0.08 & 1.52 & 1.46 \\
\hline 25 & 10.88 & 0.06 & 1.16 & 2.08 & 50 & 6.04 & 0.1 & 1.22 & 1.52 \\
\hline
\end{tabular}




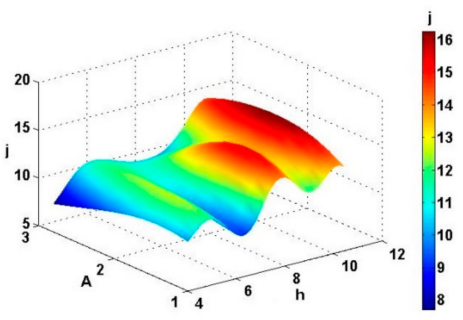

(a)

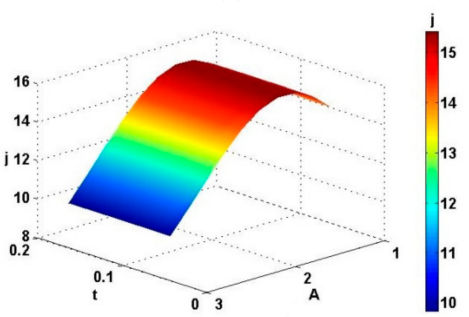

(c)

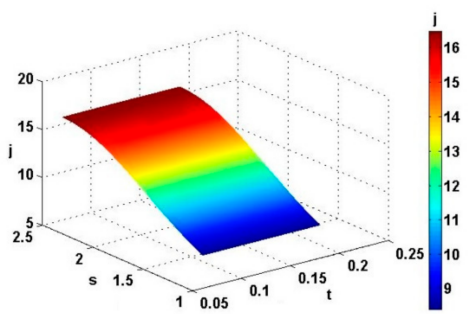

(e)

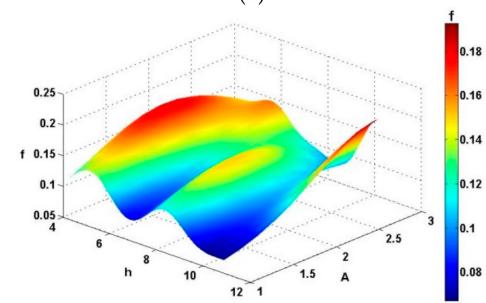

(g)

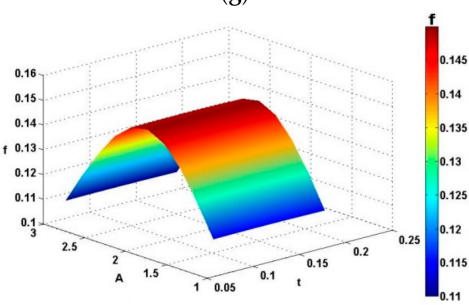

(i)

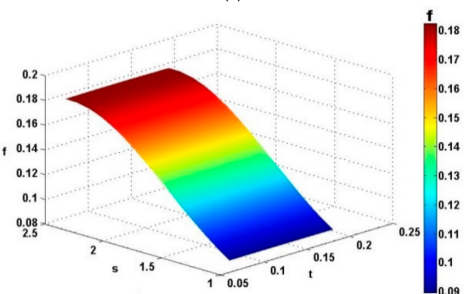

(k)

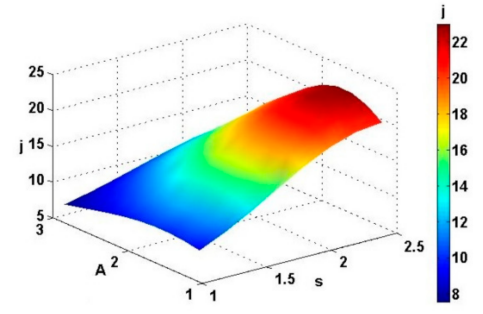

(b)

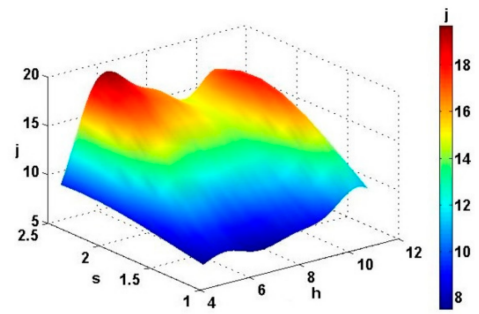

(d)

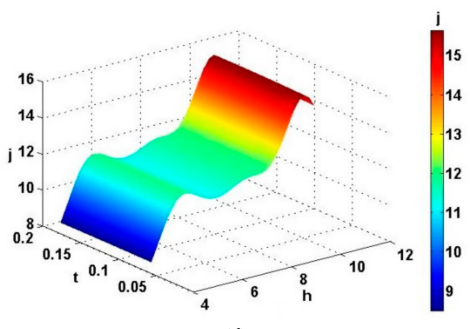

(f)

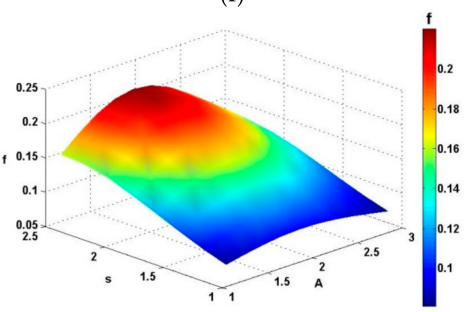

(h)

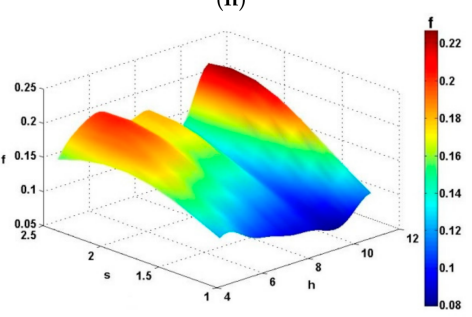

(j)

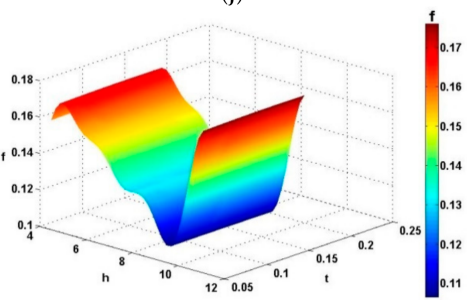

(1)

Figure A1. Non-linear relationship between parameters and performances. (a) $j$ vs. $A, h_{\text {.; }}$ (b) $j$ vs. $A, s ;$ (c) $j$ vs. $t, A ;$ (d) $j$ vs. $s, h ;(\mathbf{e}) j$ vs. $s, t ;(\mathbf{f}) j$ vs. $t, h ;$ (g) $f$ vs. $h, A ;(\mathbf{h}) f$ vs. $s, A ;(\mathbf{i}) f v s A, t ;(\mathbf{j}) f$ vs. $s$, $h ;(\mathbf{k}) f$ vs. $s, t ;(\mathbf{l}) f$ vs. $h, t$. 
Table A2. 20 sets of contrast sample points.

\begin{tabular}{cccccccccc}
\hline Code & $\begin{array}{c}\boldsymbol{h} \\
(\mathbf{m m})\end{array}$ & $\begin{array}{c}\boldsymbol{t} \\
(\mathbf{m m})\end{array}$ & $\begin{array}{c}\boldsymbol{s} \\
(\mathbf{m m})\end{array}$ & $\begin{array}{c}\boldsymbol{A} \\
(\mathbf{m m})\end{array}$ & Code & $\begin{array}{c}\boldsymbol{h} \\
(\mathbf{m m})\end{array}$ & $\begin{array}{c}\boldsymbol{t} \\
(\mathbf{m m})\end{array}$ & $\begin{array}{c}\boldsymbol{s} \\
(\mathbf{m m})\end{array}$ & $\begin{array}{c}\boldsymbol{A} \\
(\mathbf{m m})\end{array}$ \\
\hline 1 & 4 & 0.12 & 1 & 1.5 & 11 & 8 & 0.12 & 1 & 1.5 \\
2 & 6 & 0.12 & 1 & 1.5 & 12 & 8 & 0.12 & 1.4 & 1.5 \\
3 & 8 & 0.12 & 1 & 1.5 & 13 & 8 & 0.12 & 1.8 & 1.5 \\
4 & 10 & 0.12 & 1 & 1.5 & 14 & 8 & 0.12 & 2.2 & 1.5 \\
5 & 12 & 0.12 & 1 & 1.5 & 15 & 8 & 0.12 & 2.6 & 1.5 \\
6 & 8 & 0.06 & 1 & 1.5 & 16 & 8 & 0.12 & 1 & 1 \\
7 & 8 & 0.09 & 1 & 1.5 & 17 & 8 & 0.12 & 1 & 1.5 \\
8 & 8 & 0.12 & 1 & 1.5 & 18 & 8 & 0.12 & 1 & 2 \\
9 & 8 & 0.15 & 1 & 1.5 & 19 & 8 & 0.12 & 1 & 2.5 \\
10 & 8 & 0.18 & 1 & 1.5 & 20 & 8 & 0.12 & 1 & 3 \\
\hline
\end{tabular}

\section{References}

1. Arie, M.A.; Shooshtari, A.; Rao, V.V.; Dessiatoun, S.; Ohadi, M.M. Air Side Heat Transfer Enhancement Utilizing Design Optimization and an Additive Manufacturing Technique. J. Heat Transf. 2017, 139. [CrossRef]

2. Xie, G.; Asadi, M.; Sundén, B.; Zheng, S. Constructal Theory Based Geometric Optimization of Wavy Channels in the Low Reynolds Number Regime. J. Electron. Packag. 2014, 136, 031013. [CrossRef]

3. Song, Y.; Asadi, M.; Xie, G.; Rocha, L. Constructal wavy-fin channels of a compact heat exchanger with heat transfer rate maximization and pressure losses minimization. Appl. Therm. Eng. 2015, 75, 24-32. [CrossRef]

4. Kumar, A.; Wu, C.; Nayak, A.K.; Vijayan, P.K. 3D CFD simulations of air cooled condenser-III: Thermal-hydraulic characteristics and design optimization under forced convection conditions. Int. J. Heat Mass Transf. 2016, 93, 1227-1247. [CrossRef]

5. Yanagimoto, J.; Wake, Y.; Zeise, P.; Mao, H.; Shikazono, N. Design and optimization of stamping process of ultra-thin stainless sheet into bidirectionally corrugated shape for finless high-efficiency heat exchanger. CIRP Ann. Manuf. Technol. 2016, 65, 289-292. [CrossRef]

6. Wang, L.; Deng, L.; Ji, C.; Liang, E.; Wang, C.; Che, D. Multi-objective optimization of geometrical parameters of corrugatedundulated heat transfer surfaces. Appl. Energy 2016, 174, 25-36. [CrossRef]

7. Chamoli, S.; Yu, P.; Kumar, A. Multi-response optimization of geometric and flow parameters in a heat exchanger tube with perforated disk inserts by Taguchi grey relational analysis. Appl. Therm. Eng. 2016, 103, 1339-1350. [CrossRef]

8. Yarmohammadi, S.; Farhadi, M. Optimization of thermal and flow characteristics of R-404A vapor condensation inside corrugated tubes. Exp. Therm. Fluid Sci. 2016, 79, 1-12. [CrossRef]

9. Khoshvaght-Aliabadi, M.; Jafari, A.; Sartipzadeh, O.; Salami, M. Thermal-hydraulic performance of wavy plate-fin heat exchanger using passive techniques: Perforations, winglets, and nanofluids. Int. Commun. Heat Mass Transf. 2016, 78, 231-240. [CrossRef]

10. Asadi, M.; Xie, G. An Experimental Study on Heat Transfer Surface Area of Wavy-Fin Heat Exchangers. J. Therm. Sci. Eng. Appl. 2014, 6. [CrossRef]

11. Lorenzini, G.; Rocha, L.A.O. Constructal design of T-Y assembly of fins for an optimized heat removal. Int. J. Heat Mass Transf. 2009, 52, 1458-1463. [CrossRef]

12. Damavandi, M.D.; Forouzanmehr, M.; Safikhani, H. Modeling and Pareto based multi-objective optimization of wavy fin-andelliptical tube heat exchangers using CFD and NSGA-II algorithm. Appl. Therm. Eng. 2017, 111, 325-339. [CrossRef]

13. Kim, G.W.; Lim, H.M.; Rhee, G.H. Numerical studies of heat transfer enhancement by cross-cut flow control in wavy fin heat exchangers. Int. J. Heat Mass Transf. 2016, 96, 110-117. [CrossRef]

14. Ghorbanian, A.; Tahari, M.; Hatami, M. Physical optimization of a wavy porous cavity filled by nanofluids in the presence of solar radiations using the Box-Behnken design (BBD). Eur. Phys. J. Plus 2017, 132, 278. [CrossRef]

15. Lu, G.; Zhao, J.; Lin, L.; Wang, X.; Yan, W.-M. A new scheme for reducing pressure drop and thermal resistance simultaneously in microchannel heat sinks with wavy porous fins. Int. J. Heat Mass Transf. 2017, 111, 1071-1078. [CrossRef]

16. Echaroj, S.; Saeng-Uthai, S.; Promteerawong, P.; Benjapiyaporn, C.; Theerakulphisut, S.; Benjapiyaporn, J. Experiment to enhance the efficiency of tubular ice production machine using the installation of wavy fin on ice making tube. Mater. Today Proc. 2017, 4, 6296-6305.

17. Xiao, L.; Wu, T.; Feng, S.; Du, X.; Yang, L. Experimental study on heat transfer enhancement of wavy finned flat tubes by water spray cooling. Int. J. Heat Mass Transf. 2017, 110, 383-392. [CrossRef]

18. Grabski, J.K.; Kołodziej, J.A. Laminar fluid flow and heat transfer in an internally corrugated tube by means of the method of fundamental solutions and radial basis functions. Comput. Math. Appl. 2017, 75, 1413-1433. [CrossRef]

19. Mahdavi, A.; Delavar, M.A. Thermal performance of wavy fin in a compact heat exchanger duct using Galerkin method. Appl. Therm. Eng. 2017, 130, 1290-1298. [CrossRef]

20. Kim, G.W.; Rhee, G.H. Optimization study of cross-cut flow control for heat transfer enhancement in wavy fin heat exchangers: Concept of cross-cut reference length. Appl. Therm. Eng. 2018, 134, 527-536. [CrossRef]

21. Bellos, E.; Tzivanidis, C.; Tsimpoukis, D. Optimum number of internal fins in parabolic trough collectors. Appl. Therm. Eng. 2018, 137, 669-677. [CrossRef] 
22. Li, M.; Zhang, H.; Zhang, J.; Mu, Y.; Tian, E.; Dan, D.; Zhang, X.; Tao, W. Experimental and numerical Study and Comparison of Performance for Wavy Fin and a Plain Fin with Radiantly Arranged Winglets around Each Tube in Fin-and-tube Heat Exchangers. Appl. Therm. Eng. 2018, 133, 298-307. [CrossRef]

23. Adewumi, O.O.; Bello-Ochende, T.; Meyer, J.P. Constructal design of combined microchannel and micro pin fins for electronic cooling. Int. J. Heat Mass Transf. 2013, 66, 315-323. [CrossRef]

24. Xie, G.; Zhang, F.; Sundén, B.; Zhang, W. Constructal design and thermal analysis of microchannel heat sinks with multistage bifurcations in single-phase liquid flow. Appl. Therm. Eng. 2014, 62, 791-802. [CrossRef]

25. Xie, G.; Liu, J.; Liu, Y.; Sunden, B.; Zhang, W. Comparative Study of Thermal Performance of Longitudinal and Transversal-Wavy Microchannel Heat Sinks for Electronic Cooling. J. Electron. Packag. 2013, 135, 021008. [CrossRef]

26. Xie, G.; Liu, J.; Zhang, W.; Sundén, B. Analysis of Flow and Thermal Performance of a Water-Cooled Transversal Wavy Microchannel Heat Sink for Chip Cooling. J. Electron. Packag. 2012, 134, 341-379. [CrossRef]

27. Wang, C.C.; Liaw, J.S.; Li, Y.J.; Chen, W.; Li, L.Y. Air-side performance of herringbone wavy fin-and-tube heat exchangers under dehumidifying condition-Data with larger diameter tube. Int. J. Heat Mass Transf. 2012, 55, 3054-3060. [CrossRef]

28. Reddy, S.R.; Abdoli, A.; Dulikravich, G.S.; Pacheco, C.C.; Vasquez, G.; Jha, R.; Colaco, M.J.; Orlande, H.R.B. Multi-Objective Optimization of Micro Pin-Fin Arrays for Cooling of High Heat Flux Electronics with a Hot Spot. Heat Transf. Eng. 2015, 38, 1235-1246. [CrossRef]

29. Shi, H.-N.; Ma, T.; Chu, W.-X.; Wang, Q.-W. Optimization of inlet part of a microchannel ceramic heat exchanger using surrogate model coupled with genetic algorithm. Energy Convers. Manag. 2017, 149, 988-996. [CrossRef]

30. Sadeghzadeh, H.; Aliehyaei, M.; Rosen, M.A. Optimization of a Finned Shell and Tube Heat Exchanger Using a Multi-Objective Optimization Genetic Algorithm. Sustainability 2015, 7, 11679-11695. [CrossRef]

31. Kays, W.M.; London, A.L. Compact Heat Exchangers; U.S. Department of Energy Office of Scientific and Technical Information: Oak Ridge, TN, USA, 1984.

32. Xie, S.; Xie, Y.; Huang, T.; Gui, W.; Yang, C. Generalized predictive control for industrial process based on neuron adaptive splitting and merging RBF neural network. IEEE Trans. Ind. Electron. 2018. [CrossRef]

33. Guo, Z.Y.; Tao, W.Q.; Shah, R.K. The field synergy (coordination) principle and its applications in enhancing single phase convective heat transfer. Int. J. Heat Mass Transf. 2005, 48, 1797-1807. [CrossRef]

34. Liu, W.; Liu, Z.C.; Huang, S.Y. Physical quantity synergy in the field of turbulent heat transfer and its analysis for heat transfer enhancement. Sci. Bull. 2010, 55, 2589-2597. [CrossRef] 